\title{
Os problemas da razão pura e a semântica transcendental
}

\author{
Zeljko Loparic
}

Universidade Estadual de Campinas/Pontifícia Universidade Católica de São Paulo/ Pontifícia Universidade Católica do Rio Grande do Sul

resumo 0 presente artigo tem como objetivo mostrar que a teoria kantiana da possibilidade de juízos a priori, o conteúdo essencial da sua crítica da razão pura, foi elaborada no intuito de garantir a solubilidade dos problemas necessários da razão pura e que essa teoria pode ser interpretada como uma semântica transcendental (a priori).

palavras-chave possibilidade de juízo - crítica da razão pura - problemas necessários da razão pura - solubilidade - semântica transcendental.

\section{Introdução}

$\mathrm{N}$ as seções que abrem o presente trabalho, apresentarei uma reconstrução do programa kantiano de crítica da razão pura teórica, mostrando que, na formulação inicial desse programa em C rítica da raz ão pura (1781), K ant se propõe explicitar as condições nas quais um problema da razão pura teórica é solúvel. A doutrina da solubilidade desses problemas exige, entre outras coisas, que se responda a seguinte pergunta, considerada por $K$ ant tarefa fundamental da crítica da razão pura teórica: como são possíveis os juízos sintéticos a priori teóricos? Essa tarefa é solucionada no interior de uma teoria a priori da referência e do sentido dos conceitos teóricos a priori e da verdade dos juízos sintéticos a priori. Entendo que essa teoria pode e deve ser interpretada como uma semântica a priori ou transcendental.

R ecebido em janeiro de 2005. A ceito em maio de 2005.

doispontos, Curitiba, São C arlos, vol. 2, n. 2, p.113-128, outubro, 2005 


\section{4}

Com 0 tempo, Kant estendeu o seu programa de crítica da razão teórica aos problemas que a razão pura se coloca em todos os outros domínios abrangidos pelo discurso filosófico. De acordo como isso, a tarefa fundamental da filosofia transcendental passou a ser a seguinte: como são possíveis os juízos sintéticos a priori em geral? A fim de documentar aspectos centrais dessa extensão, farei algumas observações sobre o encaminhamento dado por Kant ao problema da possibilidade dos juízos sintéticos a priori da doutrina do Direito. D essa forma, fornecerei elementos relativos à realização do programa da crítica da razão pura no período de 1781 a 1797.

0 presente trabalho é baseado em resultados obtidos anteriormente, al guns dos quais são citados nas notas de rodapé. A sua novidade está na apresentação desses resultados com base em análises adicionais dos textos de Kant, inseridas no quadro geral de uma interpretação semântica do projeto kantiano da crítica da razão pura.

\section{Os problemas insolúveis da razão teórica: a motivação do programa kantiano da crítica da razão pura}

0 projeto kantiano de uma crítica da razão pura origina-se da preocupação de Kant com a incapacidade da razão humana para resolver seus próprios problemas. $\mathrm{A}$ primeira página da primeira $\mathrm{C}$ rítica começa pela frase: "A razão humana tem o destino especial em um domínio de seus conhecimentos: 0 de ser onerada por perguntas que não pode recusar, por elas Ihe serem impostas pela própria natureza da razão, mas que ela também não pode responder, pois essas perguntas ultrapassam toda a capacidade da razão humana" (KAN T-1781, A VII)1.

0 domínio em questão é o dos conhecimentos teóricos sobre a natureza. Desde a fase pré-crítica, uma das preocupações centrais do pensamento kantiano era, de fato, a incapacidade da metafísica tradicional para resolver, por sim ou por não2, os problemas filosóficos relativos à natureza, debilidade atestada pelas contradições e pela obscuridade que caracterizam as disputas entre os filósofos.

As contradições da razão dogmática podem ser ilustradas pelas famosas disputas, encontradas na correspondência Leibniz-Clark, sobre as 
propriedades do universo material considerado como um todo. Essas disputas são a fonte histórica de quatro grupos de problemas denomina dos por K ant "antinomias" da razão pura teórica. $\mathrm{N}$ a D ialética transcendental, esses problemas são demonstrados necessários e deduzidos dos princípios formais (lógicos) e materiais (semânticos) do dogmatismo tradicional. A primeira antinomia pode ser formulada como o problema de decidir qual dos lados da seguinte disjunção é verdadeiro: o mundo é finito no espaço e no tempo ou ele não é finito, mas infinito no espaço e no tempo3. Em virtude do princípio do terceiro excluído tomado na interpretação tradicional, essa disjunção é um juízo analítico. 0 ra, os dois disjuntivos podem ser reduzidos ao absurdo - isso é objeto de provas fornecidas por K ant. A tentativa da razão dogmática de resolver um dos seus problemas necessários termina na violação do princípio do terceiro excluído, ou seja, de uma lei da própria razão. Temos aqui, portanto, um exemplo do conflito da razão dogmática consigo mesma, caracterizável como contradição.

Exemplos de obscuridade são as controvérsias filosóficas, já antigas e infindáveis, relativas ao curso da história humana. N o essencial, tratase de decidir entre a tese dogmática, proposta por Epicuro, de que a ordem interna aos estados e entre as nações decorre de um acaso, e a outra tese, também dogmática, que afirma que as ações humanas obedecem a um curso regular que pode ter duas direções: conduzir "a nossa espécie, aos poucos, de um grau inferior de animalidade até 0 grau supremo de humanidade" ou, então, levar a humanidade para um "inferno de males" (KAN T-1784, 401; trad. 18). Essas disputas podem ser reduzidas à seguinte disjunção: a história humana resulta de um jogo de acaso, sem regras, ou de um jogo com regras, exibindo um curso regular? $\mathrm{N}$ a segunda al ternativa, resta saber se esse curso vai para melhor ou para pior, ficando em aberto como o melhor e o pior podem ser definidos4. Esse assunto, que não é empírico, mas a priori necessário - pois surge da própria razão, que trata de saber se a história humana, entendida como um processo natural ${ }^{5}$, pode ou não ser pensada como racional -, permaneceu sem solução na tradição filosófica, oferecendo, assim, um caso típico de obscuridade, na qual se move a razão não submetida à crítica. 


\section{6}

0 teorema da decidibilidade dos problemas teóricos da razão pura

O objetivo principal do programa kantiano da crítica da razão pura, tanto teórica quanto prática, foi precisamente evitar tais disputas, introduzindo a distinção entre os problemas solúveis e não-solúveis pela razão humana. Para K ant, a crítica da razão pura desemboca necessariamente em uma teoria de solubilidade (decidibilidade) dos problemas necessários da razão pura6.

K ant começou pelos problemas teóricos. 0 resultado central da sua crítica da capacidade solucionadora da razão teórica pode ser expressa na tese segundo a qual deve ser possível aos homens alcançar "uma certeza quanto ao saber ou não-saber dos objetos, isto é, decidir [entscheiden] sobre os objetos de suas perguntas ou sobre a capacidade ou a incapacidade de a razão julgar algo a respeito deles, portanto, ampliar com confiança a nossa razão pura ou impor-Ihe limites determinados e seguros" (KAN T-1787, B 22; trad. 32). Parafraseando, deve ser possível à razão humana decidir, com toda segurança, se um problema teórico é solúvel ou não, podendo chegar, caso o problema seja solúvel, ao conhecimento do que é procurado. C hamarei essa tese de teorema kantiano de dedidibilidade dos problemas teóricos?.

A metafísica tradicional, por não colocar o metaproblema da solubilidade dos problemas teóricos - isto é, por permanecer dogmática - , enreda-se inevitavelmente em problemas insolúveis. A nova metafísica de $K$ ant, baseada na teoria da capacidade solucionadora da razão, tem o traço distintivo de poder garantir a decidibilidade de suas indagações ou, então, abandonar a pesquisa, reconhecendo, de maneira determinada e segura, os seus limites. "N ão haver nenhuma resposta também é uma resposta", diz Kant (KAN T, 1787, B 506; trad. p. 248). Valendo-se do teorema da decidibilidade, o programa kantiano da razão pura propõe a substituição da metafísica tradicional por uma nova metafísica da natureza - um sistema de princípios a priori da razão, elaborado a partir de uma crítica prévia da capacidade da razão para resolver problemas teóricos em geral, tanto filosóficos quanto científicos (KAN T, 1787, B 869; trad. p. 409)8. 


\section{Decidibilidade e semântica transcendental}

Q uais problemas teóricos são solúveis e quais são insolúveis? A teoria kantiana da solubilidade desses problemas fornece uma resposta simples a essa indagação. " N enhuma questão", diz K ant, "concernente a um objeto dado à razão pura é insolúvel para essa mesma razão humana" (KAN T, 1787, B 505; trad. p. 247; sem grifos no original). Inversamente, “a própria questão não é nada [ist nichts]" se "não for dado a ela nenhum objeto" (KAN T, 1787, B 506n; trad. p. 248). I sso significa que "é totalmente nula e vazia [nichtig und leer] uma questão sobre a natureza daquele algo que não pode ser pensado mediante algum predicado determinado, por ser posto totalmente fora da esfera [S phäre] dos objetos que nos podem ser dados" (idem, B 507n; trad. p. 248; sem grifos no original). Dizer que uma questão é nula e vazia é o mesmo que afirmar que ela emprega predicados nãodeterminados, ou seja, conceitos vazios, sem conteúdo no domínio ("esfera") de objetos que nos podem ser dados. Lembro aqui as famosas teses de K ant de que os "pensamentos sem conteúdo" - entenda- se: sem conteúdo intuitivo - "são vazios" e de ser necessário "tornar os conceitos sensíveis (isto é, acrescentar-Ihes objeto na intuição)" a fim de poder fazer deles uso cognitivo (idem, B 75, trad. p. 57)9. Tal como na filosofia analítica atual, também em $K$ ant as questões de semântica são independentes e precedem as de epistemologia. 0 bviamente, uma questão formulada por meio de pensamentos sem conteúdo é insolúvel. Em outras palavras, ela não admite uma resposta que use predicados determinados e que fosse, por isso, determinadamente verdadeira ou falsa. Sendo assim, o problema da solubilidade de problemas teóricos pode ser reduzido, no essencial, a dois outros: 1) o da possibilidade de os conceitos usados terem um conteúdo no domínio de objetos que nos podem ser dados e b) o da possibilidade de os juízos empregados nas respostas terem a sua verdade ou falsidade determinada nesse mesmo domínio10.

De direito, essa problemática pertence à "lógica transcendental". Diferentemente da lógica formal - que "abstrai de todo o conteúdo do conhecimento, isto é, de toda referência [B ez iehung] do mesmo ao objeto, e só considera a forma lógica na relação dos conhecimentos entre si" - , a lógica transcendental é uma ciência a priori que só se ocupa das leis do entendimento e da razão "na medida em que estas são referidas [bez o- 


\section{8}

gen] a priori a objetos" (idem, B 81; trad. p. 60)11. Para tanto, a lógica transcendental procede de maneira inteiramente a priori, sem consultar a experiência, fazendo uso do conhecimento chamado "transcendental", pelo qual sabemos "que e como certas representações", entre elas os conceitos, "são aplicadas ou possíveis unicamente a priori" (ibidem; sem grifos no original). Sendo assim, a lógica transcendental pode ser interpretada como uma teoria a priori do significado de conceitose da verdade de juízos no domínio de interpretação constituído de fenômenos naturais acessíveis à intuição. Em terminologia atualizada, uma semântica a priori ou transcendental do tipo construtivista12, que fornece a resposta à pergunta principal da filosofia transcendental, tal como formulada na primeira $\mathrm{C}$ rítica, formulação que será generalizada nas obras posteriores de Kant para abranger, além de juízos a priori teóricos, todos os outros juízos a priori da razão.

Entende-se facilmente por que uma "estética" faz parte da lógica transcendental. V isto que um problema é solúvel somente se empregar exclusivamente predicados que podem ser referidos a objetos dados, a teoria da "dadidade" de objetos da natureza é forçosamente uma parte essencial da teoria dos predicados determinados. O ra, para Kant, um objeto é "dável" (dabile) - e, nesse sentido, possível - se for acessível à experiência, ou seja, se puder ser dado na intuição sensível, externa ou interna, ficando excluída a possibilidade de um objeto nos ser dado, como admite D escartes, na intuição intelectual. Essa teoria, chamada por K ant de "estética transcendental", fornece, na presente interpretação, a teoria do domínio de interpretação de juízos sintéticos a priori teóricos: a do domínio da experiência possível13.

A teoria kantiana da determinabilidade ou da possibilidade de predicados e de juízos nesse domínio segue, no essencial, o procedimento pelo qual são fixados, por um lado, a referência e o significado de conceitos da M atemática e, por outro, a verdade ou falsidade dos juízos dessa ciência: "Tomem- se como exemplo apenas os conceitos da M atemática [...]. Se bem que todos os princípios e a representação do objeto com o qual aquela ciência se ocupa sejam produzidos inteiramente a priori na mente, eles não significariam inteiramente nada se não pudéssemos sempre mostrar a sua significação [B edeutung] nos fenômenos (objetos empíricos). Por isso se requer também tornar sensivel [sinnlich zu machen] um conceito 
abstrato, isto é, mostrar na intuição o objeto correspondente a ele porque, sem isso, o conceito permaneceria (como se diz) privado de sentido, isto é, de significação [ohne Sinn, $d$. h. ohne B edeutung]. A M atemática preenche esse requisito pela construção da figura, que é um fenômeno presente aos sentidos (se bem que, na verdade, realizado de modo a priori)" (idem, B 299; trad. p. 155).

Esse procedimento de sensificação de conceitos e de princípios, praticado já na $M$ atemática grega, foi adaptado por Kant para produzir, no quadro da lógica transcendental, uma teoria da referência e do significado dos conceitos teóricos a priori em geral (filosóficos, matemáticos e físicos puros). Por exemplo, é impossível dar uma "definição real" de uma categoria, isto é," tornar compreensível a possibilidade do seu objeto" sem "descer" imediatamente às condições da sensibilidade (idem, B 300; trad. p. 155). Q uando essa condição é eliminada, "desaparece toda significação, isto é, a relação com o objeto e mediante nenhum exemplo podemos compreender que espécie de coisa é propriamente entendida com tais conceitos" (ibidem; trad. p. 156). Em resumo, sem regras de aplicação (A nwendung) das categorias à sensibilidade não é possível mostrar "como elas [as categorias] podem ter qualquer significação e validade objetiva [irgendeine B edeutung und objektive G ültigkeit]" (KAN T, 1781, A 242).

A teoria da sensificação das categorias, cuja parte central é o esquematismo transcendental, é acompanhada por uma teoria da verdade dos juízos teóricosa priori em geral, filosóficos e não-filosóficos (os matemáticos e os conceitos puros da ciência da natureza, identificada por $K$ ant com a Física de $\mathrm{N}$ ewton), teoria baseada igualmente no requisito da sensificação desses juízos. Aqui, o problema central é determinar as condições em que os juízos que empregam predicados determinados são eles próprios possíveis, no sentido de poderem ter a sua validade objetiva - sua verdade ou falsidade - determinada no domínio de dados possíveis. U sando a terminologia atual, trata-se de explicitar as condições de verdade dos juízos sintéticos teóricos a priori em geral nesse domínio. Por isso, de acordo com a segunda edição da primeira C rítica, a tarefa geral (allgemeine A ufgabe) da filosofia transcendental é precisamente a seguinte: como são possíveis os juízos sintéticos a priori teóricos (cf. KAN T, 1787, B 73; trad. p. 55)14? Com a progressiva realização do programa da crítica 
da razão, a questão da possibilidade da metafísica em geral, da M atemática pura e da ciência pura da natureza deixa de ser remetida à teoria das faculdades mentais ou das disposições do ânimo, passando a ser reformulada em termos de uma teoria de juízos.

A solução kantiana da tarefa geral da filosofia transcendental consiste basicamente em dizer que um juízo é possível se a conexão discursiva entre conceitos nele afirmada puder ser conectada, de modo apropriado, com a experiência possível, isto é, sensificada; em outras palavras, se a síntese discursiva puder ser apresentada na intuição possível. A sensificação (V ersinnlichung) é assegurada por exemplos ou "construções", a posteriori ou a priori, na experiência posśvivel. As construções a posteriori são experimentos; as a priori, produtos da imaginação transcendental, isto é, esquemas a priori, "constitutivos" ou apenas "regulativos" (heurísticos). No caso de juízos teóricos categóricos, por exemplo, a sensificação provê um terceiro intermediário, que permite juntar o conceito de sujeito com 0 de predica do. No caso de juízos categóricos a posteriori, esse terceiro é a posteriori; já no caso de juízos categóricos a priori (filosóficos, matemáticos ou físicos), ele tem de ser, além de sensível e teórico (cognitivo), também a priori.

À teoria da solubilidade dos problema da razão pura Kant adiciona a teoria dos métodos a priori de sua solução. A metodologia kantiana consiste na teoria da prova, completada por um programa a priori de pesquisa científica que fornece subsídios para a criação, pelos cientistas, de ficções úteis para a busca e a organização de fatos empíricos, bem como para a descoberta de hipóteses explicativas empíricas desses fatos. 0 método de prova kantiano é, no essencial, o método combinado de análise e síntese (cf. LO PA R IC , 2002, especialmente o cap. 2). Q uanto ao programa de pesquisa, suas características mudam de acordo com a natureza dos problemas tratados. A ssim como os filosóficos, os problemas matemáticos e físicos puros são solúveis tão-somente pelos procedimentos a priori, enquanto os empíricos competem à ciência natural e podem ser resolvidos pela pesquisa factual.

As soluções de problemas factuais são baseadas, em parte, nas dos problemas matemáticos e, em parte, no sistema dos conhecimentos a priori constituído de respostas às perguntas filosóficas. Esse sistema pode servir como quadro para a produção de "especulações" ou de "ficções heurísticas" a serem utilizadas como princípios- guia da pesquisa empíri- 
ca e para a organização dos resultados assim obtidos na forma de sistemas de leis empíricas. Exemplos de princípios-guia desse tipo encontram-se na teoria kantiana das forças fundamentais, exposta em P rinápios metafísicos da ciência da naturez $a^{15}$.

U m outro exemplo dessas ficções heurísticas são as idéias teleológicas. Elas não podem ser usadas para fazer asserções sobre a natureza, mas servem tão-somente para organizar a pesquisa empírica relativa aos seres naturais organizados (orgânicos), bem como à natureza considerada com um todo organizado. A regra geral a priori para abordar esse problema (ou classe de problemas) exige que tratemos todas as conexões efetivas (determinadas) no mundo como se (als ob) "uma unidade sistemática e dotada de propósito pudesse ser encontrada por toda a parte, in infinitum" (KANT, 1787, B 728; trad. p. 343). Esse regra é um óbvio antropomorfismo e não possui um valor de verdade determinado no domínio da experiência possível. M esmo assim, ela se revela útil como princípio regulativo para o estudo do mundo como um todo, podendo ser usado, por exemplo, como guia para a reflexão tanto sobre os corpos naturais orgânicos como sobre os não-orgânicos. C ontinuando essa linha de raciocínio, Kant dirá, na $C$ rítica da faculdade do juíz o, que, a fim de ser racional, a reflexão sobre essas coisas - ou seja, a tentativa sistemática de descobrir suas propriedades e leis fundamentais, designada como tarefa à faculdade do juízo - deve necessariamente obedecer à idéia de que "um produto orgânico da natureza é aquele no qual todo fim é, reciprocamente, meio" (KAN T, 1793, p. 295-296; trad. p. 218). Em um tal produto, comenta K ant, "nada é em vão, sem finalidade, ou atribuível a um mecanismo cego da natureza" (ibidem)16.

\section{A solução da primeira antinomia e do problema da história da espécie humana}

É dentro desse quadro semântico e metodológico que Kant oferece meios, avaliados como seguros, para que a razão possa evitar cair nas contradições internas e na obscuridade.

A sua solução da primeira antinomia, por exemplo, consiste essencialmente em uma "definição real" dos conceitos usados na sua formulação, 


\section{2}

a saber, os de mundo, tempo, espaço, finito e infinito.Todos eles são interpretados no domínio da experiência possível, de acordo com os resulta dos da estética transcendental. 0 conceito de mundo é tomado no sentido de mundo sensível; os de tempo e de espaço, no sentido de formas a priori da intuição e externa, respectivamente, e os de finito e de infinito, como determinações do tempo e do espaço sensíveis, nenhum deles referindo-se ao domínio de coisas em si, como ocorre na metafísica dogmática. À luz dessa semântica dos conceitos envolvidos, assegurada a sensificação dos mesmos, $\mathrm{K}$ ant demonstra que a tese da antinomia (" $\mathrm{O}$ mundo tem um início no tempo e é também quanto ao espaço encerra do dentro de limites") é falsa e que a antítese (" 0 mundo não possui nem um início nem limites no tempo, mas é infinito tanto com respeito ao tempo quanto com respeito ao espaço") é verdadeira, solução que preserva a validade do princípio do terceiro, ainda que apenas no domínio da experiência possível e evita que a razão entre em contradição consigo mesma.

0 segundo problema mencionado anteriormente, o do curso da história natural da espécie humana, é resolvido por Kant em 1784 no quadro da sua teleologia da natureza, como explicitada na primeira $\mathrm{C}$ rítica. A plicada à história, essa doutrina oferece um certo número de princípios "como se", segundo os quais é permitido conceber a história de maneira antropomorfa, como se fosse um processo natural ocorrendo de acordo com um propósito. N o presente contexto, esse propósito é pensa do por Kant como um (sábio) plano da natureza, o fim último do qual é a realização de uma ordem pública baseada na constituição civil e capaz de se preservar como um autômato (tal como ocorre com o sistema solar). Esses princípios, não determinantes e meramente reflexivos - não sendo, portanto, nem verdadeiros nem falsos - são, contudo, próprios para serem usados como guias (L eitfaden) a priori, isto é, como programa a priori da pesquisa empírica no campo da história humana, visando à elaboração de uma apresentação sistemática desse processo como um progresso em direção de um certo fim racional (KAN T, 1784, p. 408-410). N o quadro desse programa, K ant descarta a especulação dogmática de Epicuro não como falsa, mas como incompatível com a "doutrina teleológica da natureza", doutrina justificada na primeira C rítica como formulação das exigências decorrentes da economia interna da razão humana e não 
como objetivamente verdadeira. A tese oposta, que afirma o progresso para melhor, é aceita, não como um juízo determinadamente verdadeiro, mas como um princípio racional de reflexão sobre o que acontece com a espécie humana.

\section{0 desenvolvimento do programa da crítica da razão pura}

U ma das primeiras e mais significativas aplicações da semântica transcendental e da teoria da prova nela baseada encontra-se em P rinápios metafísicos da ciência da natureza. N esta obra, publicada em 1786, Kant fornece regras para determinar "a realidade objetiva, isto é, o significado e a verdade" dos conceitos e das proposições fundamentais da metafísica da naturez a (KAN T, 1786, p. XX III). D essa maneira, ele entende prestar um serviço "excelente e indispensável" a essa metafísica, na medida em que providencia "exemplos (casos in concreto) que realizam os conceitos e os teoremas dessa última", isto é, "atribuem sentido e significação [Sinn und B edeutung] a meras formas de pensamento" constitutivas dessa metafísica (ibidem). A "realização" dos conceitos e dos teoremas da metafísica da natureza é, por sua vez, o fundamento das provas a priori desses teoremas que constituem a parte pura da Física newtoniana reconstruída por K ant.

Já em 1785, em Fundamentação da metafísica dos costumes, Kant indaga sobre a possibilidade de juízos a priori sintético-práticos, do tipo do imperativo categórico, formulado pela primeira vez nessa mesma obra. Ainda que não consiga resolver esse problema (uma solução só será apresentada em C rítica da razão prática, de 1788, no contexto da teoria do fato da razão ${ }^{17}$ ), K ant dá aqui um primeiro passo na tentativa de enquadrar toda a filosofia pura na filosofia transcendental. Isso significa, de acordo com a interpretação aqui defendida, que o problema da possibilidade passa a ser colocado com respeito aos juízos sintéticos a priori em geral. De fato, depois de ter considerado os juízos a priori sintético-práticos, Kant formula e tenta resolver o problema da possibilidade de juízos sintéticos a priori estéticos (de gosto e sobre o sublime), jurídicos, da doutrina da virtude e históricosis.

Para finalizar, assinalo aqui alguns aspectos do encaminhamento que K ant deu ao problema da possibilidade dos juízos sintéticos a priori jurídi- 


\section{4}

cos. De acordo com o Kant tardio, a filosofia prática deveria constar de uma "metafísica dos costumes" e de uma "antropologia moral" (KAN T, 1797 , p. 12). A primeira parte contém princípios a priori "objetivos" que dispõem sobre a "liberdade tanto no uso externo quanto interno do arbítrio" e que foram expostos em P rinápios metafísicos da doutrina do D ireito. Da segunda parte, a antropologia moral, K ant esboçou apenas um projeto, segundo o qual essa disciplina deveria tratar "das condições subjetivas da natureza humana que obstam ou auxiliam as pessoas no aumprimento [A usführung] das leis de uma metafísica dos costumes". Ela teria de se ocupar, ainda, "do desenvolvimento, difusão e fortalecimento dos princípios morais (na educação escolar e na instrução popular), e de outros ensinamentos e preceitos similares baseados na experiência" (ibidem) ${ }^{19}$.

Essa distinção é uma novidade em relação à primeira C rítica. $N$ essa obra, K ant opõe a filosofia prática, em particular a moral pura - que trata de princípios "que determinam e tornam necessários a priori o fazer e 0 deixar de fazer", - à antropologia, concebida como uma teoria empírica de caráter científico, ao afirmar que "a metafísica dos costumes é propria mente a moral pura, na qual nenhuma antropologia (nenhuma condição empírica) é colocada como fundamento" (KAN T-1787, B 869-70; trad. 409). Essa tese é mantida em Prinápios metafísicos da doutrina do $D$ ireito, obra publicada como primeira parte de M etafísica dos costumes (1797). Entretanto, aqui, o problema da fundamentação e da validade das leis a priori da doutrina do Direito e da virtude é formulado de acordo com os resultados obtidos em C rítica da raz ão prática (1788), passando a exigir a demonstração da aplicabilidade imanente das leis práticas, isto é, da possibilidade de essas leis terem vigência no domínio das ações efetivamente executáveis pelo agente humano livre. Essa mudança de enfoque refletese na seguinte observação de K ant: "embora a metafísica dos costumes não possa ser fundamentada na antropologia, contudo, ela pode ser aplicada a ela" (KAN T, 1797, p. 11). U ma das principais inovações da doutrina do $D$ ireito, inspirada na segunda $C$ rítica, é precisamente a de acrescentar ao domínio de objetos possíveis, especificado pela primeira C rítica, 0 domínio de ações executáveis livremente, abrindo o caminho para a elaboração de uma teoria a priori de aplicação dos conceitos e leis da metafísica dos costumes nesse último domínio, isto é, para uma semântica a priori como parte da filosofia prática de Kant. Essa é uma tarefa imprescindível. K ant 
escreve: " $M$ as do mesmo modo que hão de existir, em uma metafísica da natureza, também princípios de aplicação [Prinzipien der A nwendung] daquelas proposições universais supremas sobre uma natureza em geral aos objetos da experiência, uma metafísica dos costumes tampouco poderá permitir que faltem esses mesmos princípios, de modo que teremos de tomar como objeto a natureza particular do homem, que é conhecida somente pela experiência, a fim de mostrar nela as conseqüências dos princípios morais universais" (ibidem).

Em outras palavras, a constituição de uma metafísica dos costumes, como proposta em Prinápios metafísicos da doutrina do D ireito, implica, como subtarefa necessária, a elaboração dos princípios de aplicação das proposições fundamentais da metafísica dos costumes no domínio das ações humanas ${ }^{20}$. Essa incumbência é concebida, por $K$ ant, em exato paralelo com a tarefa, executada em Prinápios metafísicos da ciência da naturez a (1786), de atribuir sentido e significação às estruturas discursivas ("formas do pensamentos") da metafísica da natureza21. Esse paralelo não elimina, mas sublinha, uma diferença significativa entre a teoria kantiana do "sentido e significado" dos conceitos a priori naturais e morais: enquanto os primeiros são interpretados sobre os objetos da experiência cognitiva, os segundos são referidos a ações exeqüíveis livremente, acessíveis somente em uma experiência que, por servir de fundamento da antropologia moral, poderia também ser chamada moral. A qui se abre um campo de pesquisa fascinante, ainda muito pouco explorado e essencial para a completude de uma leitura semântica do projeto crítico de Kant.

\footnotetext{
${ }^{1}$ As obras de Kant são citadas de acordo com a paginação das edições originais alemãs, indicadas pelo ano de publicação. Em alguns casos, as traduções existentes, referidas na bibliografia, foram modificadas.

2 Kant dá destaque aos problemas de prova, considerando secundários, mas não sem importância, os de descoberta.

3 Essa paráfrase da primeira antinomia é baseada na reconstrução da sua forma lógica apresentada em Loparic (1990). A formulação original de K ant é a seguinte: tese: "O mundo tem um início no tempo e é também quanto ao espaço encerrado dentro de limites"; antítese: "0 mundo não possui um início nem limites no tempo, mas é infinito tanto com respeito ao tempo quanto com respeito ao espaço" (KAN T, 1787, B 455; trad. p. 223). 0 problema consiste em decidir qual das duas alternativas é verdadeira.
} 


\section{6}

${ }^{4}$ As disputas filosóficas sobre esse tema, que começaram com E picuro e Platão, somam-se às discussões teológicas sobre a questão de saber se a história humana realiza os desígnios da suprema sabedoria do criador, governador e juiz do mundo ou se, sendo obra de acaso, ela não manifesta qual quer sentido racional.

5 Estou considerando aqui o conceito kantiano de história humana como desenvolvido em I déia de uma história universal do ponto de vista cosmopolita, de 1784. Esse conceito naturalista de história será abandonado pelo Kant tardio em favor de um conceito definido em termos da doutrina do Direito de 1797.

6 Essa teoria permitirá a K ant anunciar o fim das disputas “indecidíveis" e o estabelecimento da "paz perpétua” na filosofia (cf. KAN T, 1796).

7 U ma exposição mais detalhada desse teorema encontra-se em Loparic (2002, cap. 1).

8 Kant distingue dois grupos de problemas teóricos: filosóficos e não-filosóficos ou científicos. O s primeiros são gerados pelos princípios constitutivos da própria razão, sendo, por isso, necessários; os segundos decorrem de interesses ocasionais, sendo, portanto, opcionais. Estes últimos podem ser divididos em puros (matemáticos e físicos puros) e empíricos.

${ }^{9} \mathrm{C}$ omo se vê, a tese de que os conceitos não-sensificados são vazios é intimamente ligada à concepção kantiana de perguntas vazias, um ponto raramente notado nas reconstruções tradicionais do programa crítico de K ant.

10 Para uma análise mais aprofundada da teoria kantiana dos problemas, cf. Loparic (1988).

$11 \mathrm{~N}$ a tradução, sigo a correção dessa frase proposta por Erdmann.

$12 \mathrm{U}$ m estudo exaustivo da lógica transcendental de Kant como uma teoria a priori da referência dos conceitos e da verdade de juízos no domínio de experiência posśvel pode ser encontrado em Loparic (2002).

13 Portanto, não se trata de uma psicologia, seja empírica, seja a priori.

14 D ou como óbvio que demonstrar a possibilidade de um juízo, que ele pode ser verdadeiro ou falso no domínio de experiência possível, não é o mesmo que demonstrar que ele é verdadeiro ou falso. A primeira prova pertence à semântica, pura ou empírica, a segunda, à epistemologia.

15 Sobre a heurística kantiana, cf. Loparic (1983; 2002, cap. 9). A metapsicologia de Freud é um produto longínquo desse mesmo programa de pesquisa empírica (cf. FU LGEN CIO, 2003; LO PAR IC, 2003c).

$16 \mathrm{U}$ m exemplo do emprego desse mesmo procedimento é oferecido já na primeira C rítica: "Com efeito, se com respeito à figura da terra (arredondada, embora um tanto achatada), das montanhas, dos mares etc., de antemão admitimos [...] propósitos sábios de um criador, então podemos, por essa via, faz er uma porção de descobertas" (KAN T, 1787, p. B 715; trad. p. 338; sem grifos no original).

17 Essa tese é exposta e defendida em Loparic (1999).

18 Esse ponto foi explicitado com detalhes em Loparic (2003b).

doispontos, Curitiba, São C arlos, vol. 2, n. 2, p.113-128, outubro, 2005 
19 Claro está que a antropologia moral, tal como projetada por K ant na sua doutrina do Direito, deve ser distinguida tanto da psicologia empírica como da antropologia "fisiológica" a qual, sendo parte da ciência teórica da natureza, "pesquisa aquilo que a natureza faz do homem" - e aproximada da pragmática, cujo objeto é aquilo que o homem, "enquanto ser que age livremente, faz de si mesmo ou pode e deve fazer" (KAN T, 1798, p. IV).

${ }^{20} \mathrm{~A}$ questão da possibilidade dos juízos sintéticos a priori do D ireito foi abordada detalhadamente em Loparic (2003b).

21 Sobre esse paralelo, cf. Loparic (2003a).

\section{Referências bibliográficas}

FU LGEN CIO, L. 2003. As especulações metapsicológicas de Freud.

$N$ atureza humana, v. 5, n. 1, p. 129-173.

KAN T, I. 1781 [2a ed.: 1787]. Kritik der reinen Vernunft. In: Immanuel K ant W erkausgabe.V. III-IV. Ed. Weischedel. Frankfurt am M ain: Suhrkamp, 1974.Tradução: . 1980. C rítica da razão pura.

Trad.V. R ohden e U. M oosburguer, baseada na edição de 1787 (CR P, B). São Paulo: A bril Cultural.

. 1784. Idee zu einer allgemeinen Geschichte in weltbürgerlicher Absischt. In: . Immanuel $\mathrm{K}$ ant W erkausgabe. V. X I. Ed. Weischedel.

Frankfurt am M ain: Suhrkamp, 1974. Tradução: 1984. Idéia de uma história universal do ponto de vista cosmopolita. Trad. R . Terra e R . $N$ aves. São Paulo: B rasiliense.

. 1785. G rundlegung der M etaphysik der Sitten. In: . Immanuel K antW erkausgabe. V.VII. Ed. Weischedel. Frankfurt am M ain: Suhrkamp, 1974. Tradução: . 1988. F undamentação da metafísica dos costumes. Lisboa: ed. 70.

. 1786. M etaphysische A nfangsgründe der $N$ aturwissenschaft [Princípios metafísicos da ciência da natureza]. In: . Immanuel $\mathrm{K}$ ant W erkausgabe. V. IX . Ed. Weischedel. Frankfurt am M ain: Suhrkamp, 1974.

1788. Kritik der praktischen Vernunft. In: . Immanuel $\mathrm{K}$ ant W erkausgabe.V.VII. Ed. Weischedel. Frankfurt am M ain: Suhrkamp, 1974.Tradução: . 1997. C rítica da raz ão prática. Lisboa: ed. 70. 
1793. K ritik der U rteilskraft. In: . Immanuel Kant

W erkausgabe.V. X. Ed. Weischedel. Frankfurt am M ain: Suhrkamp, 1974.

Tradução: . 1993. C rítica da faculdade do juíz 0. 2ª ed. Trad.V.

$\mathrm{R}$ ohden e A. M arques. $\mathrm{R}$ io de Janeiro: Forense U niversitária.

1796.Verkündigung des nahen Abschlusses einesTraktats zum

ewigen Frieden in der Philosophie. In: . Immanuel $\mathrm{K}$ ant

W erkausgabe.V. XI. Ed. Weischedel. Frankfurt am M ain: Suhrkamp, 1974.

1797. D ie M etaphysik der Sitten. In: . Immanuel $\mathrm{K}$ ant

W erkausgabe.V.VIII. Ed. Weischedel. Frankfurt am M ain: Suhrkamp, 1974.Tradução: 2003. M etafísica dos costumes. São Paulo: Edipro.

1798. Anthropologie in pragmatischer Hinsicht. In:

Immanuel K ant W erkausgabe. V. X II. Ed. Weischedel. Frankfurt am M ain: Suhrkamp, 1974.

LO PAR IC , Z. 1983. "H eurística kantiana", in: C adernos de H istória e Filosofia da C iência, n. 5, p. 73-89.

. 1988. "System-Problems in Kant", in: Synthese, v. 74, n. 1, p. 107-140. . 1990. "T he Logical Structure of the First Antinomy", in: K antStudien, v. 81, n. 3, p. 280-303.

1999. "O fato da razão - uma interpretação semântica”, in:

A nalytica, v. 4, n. 1, p. 13-55.

2002. A semântica transcendental de $K$ ant. $2^{a}$ ed. C ampinas: UNICAMP.

.2003a. As duas metafísicas de Kant. In: O LIVEIR A, N . F. \& SOU ZA, D. G. (orgs.). Justiça e política. H omenagem a O tfried $\mathrm{H}$ öffe. Porto A legre: PU C - R S.

. 2003b. 0 problema fundamental da semântica jurídica de Kant. In: SM IT H , P. J. \& W R IGLEY, M . B. (orgs.). 0 filósofo e a sua história. U ma homenagem a $\mathrm{O}$ swaldo Porchat. C ampinas: U N ICAM P. .2003c: "D e K ant a Freud: um roteiro", in: N atureza humana, v. 5, n. 1, p. 231-245. 